Raghad A Al-Askary BDS, MSc (Lec.)

Sabah A Ismail BDS, MSc (Asst. Prof.)

Nawal A Al-Sabawi BDS, MSc (Lec.)

\section{Bond Strength of Endodontic Sealers to Gutta Percha and Dentin}

Department of Conservative Dentistry College of Dentistry, University of Mosul

Department of Conservative Dentistry College of Dentistry, University of Mosul

Department of Conservative Dentistry College of Dentistry, University of Mosul

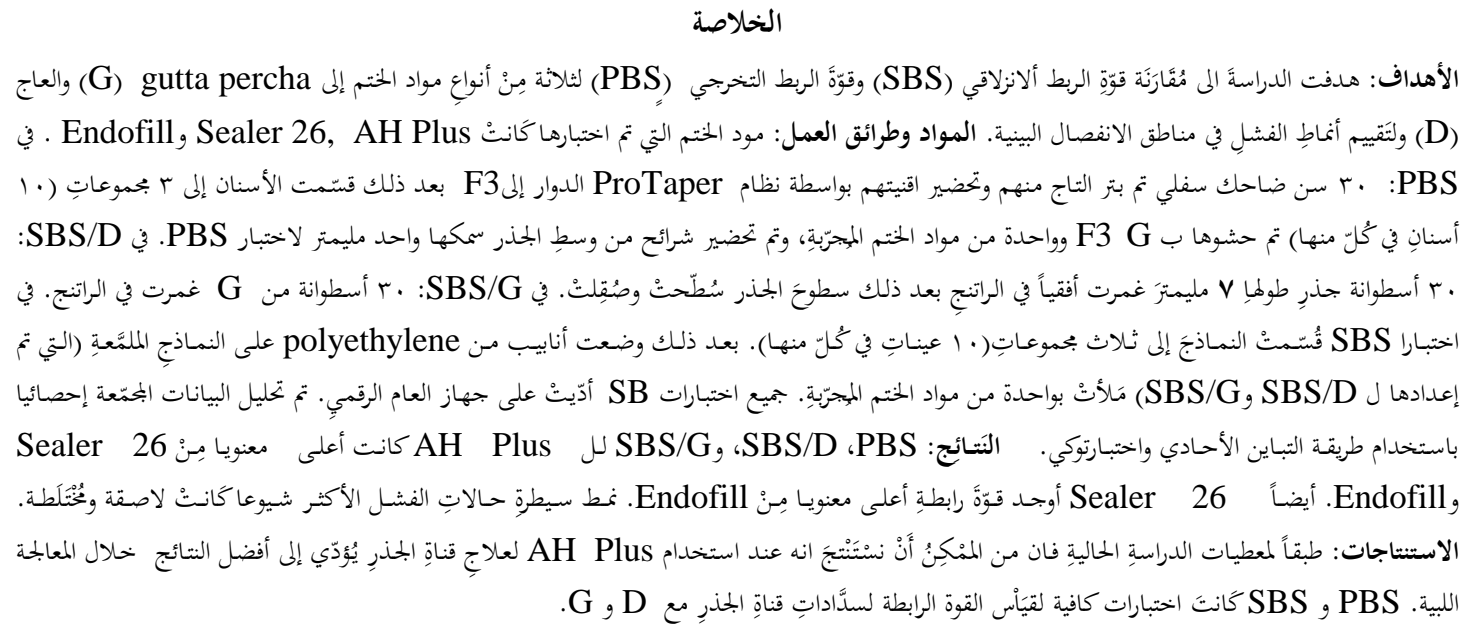

\title{
ABSTRACT
}

Aims: The aims of present study were to compare shear bond strength (SBS) and push-out bond strength (PBS) of three types of sealers to gutta percha (G) and dentin (D) and to assess failure modes at debonded interfaces. Materials and Methods: Sealers tested were AH Plus, Sealer 26, and Endofill. In PBS, 30 mandibular premolar decoronated and instrumented with rotary ProTaper to F3 then teeth were divided into 3 groups (10 teeth in each) and obturated with $F 3$ proTaper $\mathrm{G}$ and one of tested sealer, $1 \mathrm{~mm}$ mid root slices were prepared for PBS test. In SBS/D, 30 root cylinders $7 \mathrm{~mm}$ length were embedded horizontally in resin then root surfaces were flattened and smooth. In SBS/G, $30 \mathrm{G}$ cylinders were embedded in a resin. In both SBS tests, specimens were divided into three groups, 10 samples each then polyethylene tubes positioned on polished specimens (prepared for SBS/D and SBS/G) filled with one of the tested sealer. All BS tests were performed on digital universal testing machine. Collected data analyzed statistically using one way ANOVA and Tukey test. Results: PBS, SBS/D, and SBS/G for AH Plus significantly higher than Sealer 26 and Endofill. Also Sealer 26 exhibited significantly higher bond strength than Endofill. Predominance mode of failures were adhesive and mixed. Conclusions: According to the finding of present study, it can be concluded that the $\mathrm{AH}$ Plus for root canal therapy produce better results in endodontic. PBS and SBS were sufficient tests to measure bond strength of root canal sealers to $\mathrm{G}$ and $\mathrm{D}$.

Key words: Shear bond strength, Push out strength, Endodontic sealers.

Al-Askary RA, Ismail SA, Al-Sabawi NA. Bond Strength of Endodontic Sealers to Gutta Percha and Dentin. Al-Rafidain Dent J. 2013; 13(2): 282-289.

Received: $23 / 11 / 2011 \quad$ Sent to Referees: $1 / 12 / 2011$

Accepted for Publication: 22/4/2012

\section{INTRODUCTION}

Obturation of the root canal system is a very critical determinant of the success or failure of endodontic treatment, as it directly affects the outcome of endodontic therapy. It is an integral component in promoting periapical healing and preventing disease progression. ${ }^{(1)}$

Gutta percha has universally been accepted as the gold standard for root canal filling materials as it appears to be the least toxic and tissue irritating root canal filling material available. However, GP 
does not adhere to the dentinal walls and consequently a sealing agent is required. ${ }^{(2)}$

Root canal sealers work as lubricants for $\mathrm{G}$ cones, adhere for $\mathrm{G}$ and $\mathrm{D}$, assist in filling irregularities in canal walls and fill additional canals. The ability to adhere to D seems to be an important feature of a root canal filling material. Adhesion appears desirable for two reasons. In a static situation, it should prevent fluid percolation between the $G$ and the canal wall. In a dynamic situation, it should prevent dislodgement of the root filling, thereby reducing the risk of contamination. ${ }^{(3)}$

Different types of sealer have been introduced to endodontics, including those based on zinc oxide eugenol, glass ionomer, calcium hydroxide, and a range of resins base type sealers which have been used for many years. ${ }^{(4)}$

Several studies have investigated the adhesion of different types of root canal sealers to root $D$ and $G$ using different types of tests for assessment of sealers adhesion. Among the mechanical tests, stands out the SBS test, in which the force is applied parallel to the interface between the material and the tested surface. This test has been used to measure the bond strength of endodontic sealers to $\mathrm{D}$ and $\mathrm{G}^{(5,6)}$ On the other hand, more recently, a PBS test has been described to measure the bond between sealer, canal wall and the core material, it is intended to assess the extent to which the sealer and core material are bonded into a solid mass as well as the strength of the bond to the canal wall. $^{(7,8,9)}$

The purpose of present study was to measure and compare SBS and PBS of three types of sealers (zinc oxide eugenol base sealer (Endofill), and two resin based sealers (Sealer 26 and AH Plus)) to G and Dentin. Also, to assess the failures modes on debonded surfaces of these different sealers.

\section{MATERIALS AND METHODS}

Endodontic Sealers Tested:

Sealers tested in this study were zinc oxide eugenol (ZOE) based sealer (Endofill (Switzerland)), and two resin based sealers (calcium hydroxide resin based sealer (Sealer 26) (Dentsply, Rio de Janeiro, RJ, Brazil) and AH Plus (Dentsp- ly, De Trey GmbH, Germany)). Each type of sealers was mixed and prepared according to the manufacture instructions.

Push Out Bond Strength, Dentin (PBS/D):

Thirty freshly extracted mandibular premolars with a single straight canal and completely formed apex were selected and stored in $10 \%$ formalin. Then teeth were decoronated at $16 \mathrm{~mm}$ from the apex using diamond disc bur and a size $10 \mathrm{~K}$-file (Mani, Inc. Japan) was passed $1 \mathrm{~mm}$ beyond the apex of each canal until being visible at the apical foremen and the working length was recorded as being $1 \mathrm{~mm}$ less than that length. All root canals were instrumented with ProTaper (NiTi) rotary instrument to size F3 using contra-angle rotary hand piece (Endo-Mate DT, NSK NAKANISHI, INC., JAPAN). The speed of rotation was maintained at $250 \mathrm{rpm}$ and torque $3 \mathrm{Nm}$. Sodium hypochlorite (2\% $\mathrm{NaOCl}, 2 \mathrm{ml}$ ) was used for irrigation between each file size. After completion of canal preparation, the canals were rinsed with $5 \mathrm{ml} 15 \%$ ethylenediamine tetraacetic acid (EDTA) to minimize the residual effect of $\mathrm{NaOCl}$ on free radical polymerization. A final rinse of $5 \mathrm{ml}$ distilled water was used to remove any remnant of the irrigating solution. Canals were dried using paper points. The teeth were kept moist at all times by wrapping them in saline soaked gauze. The teeth were then randomly divided into three groups according to the type of sealer used (10 specimens on each group). For each tooth, the canal filled using a main cone, ProTaper F3 master cone which was matched to the final master file size. Sealers were prepared according to manufacturers instructions, and then introduced into the root canal orifices with lentula spiral, also G cone was coated with the sealer prior to its placement into the canal. After that, Coronal and apical parts of the canal were sealed with composite resin to avoid entrance of fluid inside the canal. All samples were then stored at $37^{\circ} \mathrm{C}$ and $100 \%$ humidity for $48 \mathrm{~h}$ to allow the sealer cements to set completely.

Teeth were then sectioned using a diamond disc perpendicular to their long axis at low speed with constant water cooling. A $1 \mathrm{~mm}$ thick section of mid-root D was 
prepared, at a level calculated to yield a apical canal diameter slightly greater than $0.8 \mathrm{~mm}$ (based on main cone size and taper). Both apical and coronal aspects of each sample were photographed by digital stereomicroscope (X 40) (Motic, Taiwan) and examined before testing to confirm a circular canal shape and that the sealer filled the entire canal space without voids (Figure (1)). If the canal was not circular in shape or there was any void in the sealer, it was excluded from the experiment and a replacement tooth prepared in the same way.

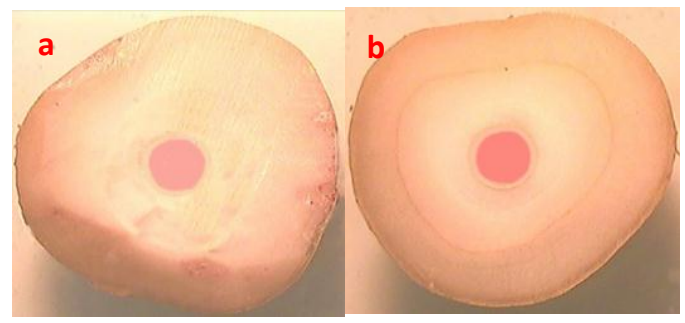

Figure (1): Prepared sample for PBS. (a): Apical aspect. (b): Coronal aspect.

After that, the samples were aligned over a $1 \mathrm{~mm}$ diameter circular hole along the center of an acrylic block (10 mmthick and $16 \mathrm{~mm}$ diameter). The samples were mounted in an apical to coronal direction to avoid any constriction interference due to root canal taper during push out testing. The filling material was loaded with a $0.8 \mathrm{~mm}$ diameter cylindrical stainless steel plunger which was mounted in the upper part of a digital universal testing machine (TERCO, MT, 3037, Sweden) (Figure (2)) and should provide almost complete coverage over the main cone without touching the canal wall.

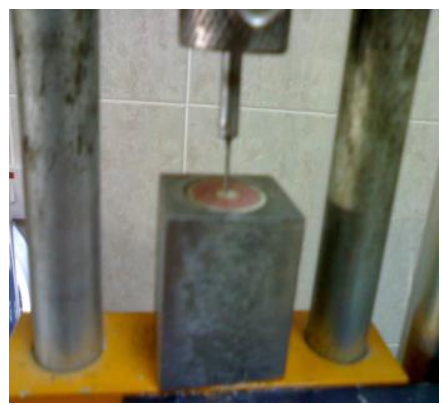

Figure (2): Sample fixed on digital universal testing machine for PBS/D.
The test was conducted at a cross head speed of $0.5 \mathrm{~mm} / \mathrm{min}$. The highest value recorded when failure occur was taken as the PBS. The area under load was calculated by $1 / 2 \times$ (circumference of coronal aspect + circumference of apical aspect) $x$ thickness, in which the diameter of apical and coronal canal were measured by Motic Image software connected to digital stereomicroscope. The PBS in Mpa was calculated from force $(\mathrm{N})$ divided by area in $\mathrm{mm}^{2}(7,8,9,10,11,12)$

Shear Bond Strength Test, Dentin $(S B S / D)$ :

This test was carried out on thirty freshly extracted mandibular premolars which stored in $10 \%$ formalin. To maintain uniformity of root length the crown of all teeth were cut with a diamond disc to obtain a $15 \mathrm{~mm}$ long root, then middle 7 $\mathrm{mm}$ of root were used for the study by cutting $4 \mathrm{~mm}$ from apical and coronal part of the root. Buccal surface of the root was shaved with wet 100 grit sand paper in an attempt to expose the dentin. Then, specimens were centered in polyester rings (10 $\mathrm{mm}$ thick and $16 \mathrm{~mm}$ diameter) and embedded in acrylic resin with the buccal root surface upwards. After resin polymerization, the dentin side of the specimens was then submitted to 15 -s polishing cycles with wet 180-, 220-, 300- , 400- and 600-grit sandpaper, sequentially. All the samples were rinsed with $2 \mathrm{ml}$ of $2 \%$ $\mathrm{NaOCl}$ then were rinsed with $5 \mathrm{ml} 15 \%$ EDTA and finally with $5 \mathrm{ml}$ of distilled water, then dentin was dried with a cotton roll. The teeth were then randomly divided into three groups according to the type of sealer used (10 specimens on each group). After that, polyethylene tubes (length $=7$ $\mathrm{mm}$; inner diameter $=3 \mathrm{~mm}$; outer diameter $=4 \mathrm{~mm}$ ) were placed with one open side contacting the middle third of the polished flat dentin perpendicular to its surface and fixed with a soft wax, after that filled with one of the tested sealers using a syringe. The specimens were stored in a humidifier at $37^{\circ} \mathrm{C}$ for 48 hours, and thereafter dried were subjected to the SBS test. Specimens were fixed on the digital universal testing machine (Figure (3)) and shearing force was applied at crosshead speed of $0.5 \mathrm{~mm} / \mathrm{min}$ until debonding of the root surface along the sealer interface was ob- 
tained. Interfacial shear strength was calculated by dividing the maximum load recorded on failure $(\mathrm{N})$ with the circular bonding area $\left(\mathrm{mm}^{2}\right)$ and expressed in Mpa. $^{(5,6,7)}$

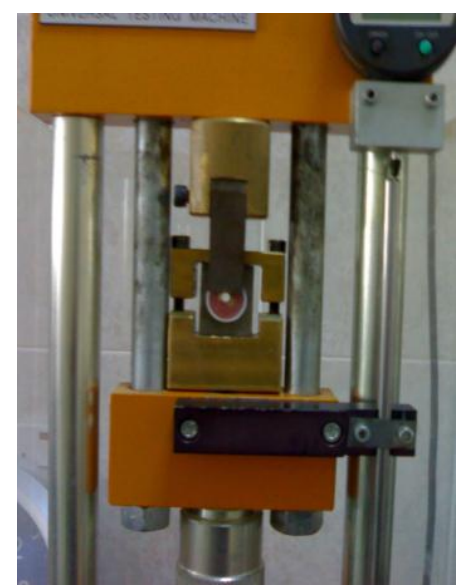

Figure (3): Sample fixed on digital universal testing machine for SBS/D.

\section{Shear Bond Strength Test, Gutta-Percha $(S B S / G)$ :}

Thirty specimens were fabricated as follows: a red wax cylinder (diameter $=$ $6 \mathrm{~mm}$ and height $=3 \mathrm{~mm}$ ) was centered in an polyester ring $(10 \mathrm{~mm}$-thick and $16 \mathrm{~mm}$ diameter) and acrylic resin was poured over the wax until the ring was filled. After resin polymerization, the wax was removed and replaced by G. Standardized size 80 cones of $G$ were softened by short immersion (15 second) in a thermostat controlled water bath $\left(45 \pm 3^{\circ} \mathrm{C}\right)$, and compacted with a larger plugger into the previously described cavity. A glass slab was placed over this set with $100 \mathrm{~N}$ load on it until the $\mathrm{G}$ hardened. The specimens were polished to ensure flattened surfaces in the same way as described for SBS/D. Specimens were then randomly divided into three groups according to the type of sealer used (10 specimens on each group). Polyethylene tubes containing one of the tested sealer was centered on the guttapercha and allowed to set as described

SBS/D. Next, the specimens were dried and subjected to SBS test (Figure (4)), as described for SBS/D. ${ }^{(3,7)}$

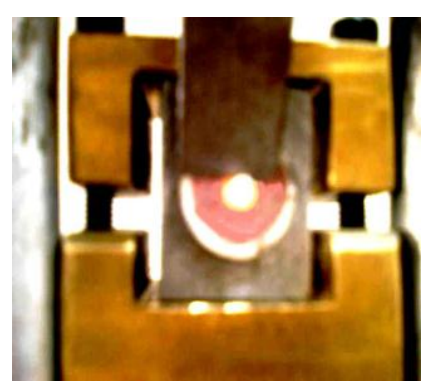

Figure (4): Sample fixed on digital universal testing machine for SBS/G.

\section{Mode of Failures:}

Each sample was viewed at 40X magnification digital stereomicroscope to determine the failure mode and put into one of the following categories: (1) adhesive (at the Sealer/D (S/D) or S/G interface) (2) combination adhesive at both the S/D and S/G interface, (3) Cohesive at S, and (4) mixed in both adhesive and cohesive modes. ${ }^{(7,9)}$

\section{RESULTS}

One way analysis of variance and Tukey post Hoc multiple range tests $(p \leq 0.05)$ were performed to evaluate the differences on BS among tested sealers. One way analysis of variance demonstrated a significant differences on the BS among tested sealers as shown in Table (1).

Tukey test revealed that PBS, SBS/D, and SBS/G for AH Plus significantly higher than Sealer 26 and Endofill. Result also showed that Sealer 26 had significantly higher bond strength to $G$ and $D$ than Endofill at different BS tests used in this study as shown in Table (2).

The percentage of mode of failures of the different sealers were listed in Table (3). The most common mode of failures among different sealers tested by different BS tests were adhesive and mixed (Figure (5)). 
Table (1): One way analysis of variance for the differences on bond strength among tested endodontic sealers.

\begin{tabular}{llccccc}
\hline & Sum of Squares & df $^{* *}$ & Mean Squares & F-value & $\boldsymbol{p}$-value \\
\hline PBS/D & Between Groups & 27.621 & 2 & 13.810 & 49.813 & 0.000 \\
& Within Groups & 2.81 & 27 & 0.277 & & \\
& Total & 1.60 & 29 & & & \\
SBS/DD & Between Groups & 42.71 & 2 & 21.233 & 62.142 & 0.000 \\
& Within Groups & 9.225 & 27 & 0.342 & & \\
& Total & 1.8 & 29 & & & \\
SBS/G & Between Groups & 29.067 & 2 & 14.533 & 87.260 & 0.000 \\
& Within Groups & 4.497 & 27 & 0.167 & & \\
& Total & 33.564 & 29 & & & \\
\hline
\end{tabular}

$* \mathrm{df}=$ degree of freedom. $* P \leq 0.05$ mean significant different exist.

Table (2): Tukey test for the differences on bond strength among tested endodontic sealers.

\begin{tabular}{cccc}
\hline \multirow{2}{*}{ Tested Sealers } & \multicolumn{3}{c}{ Mean(Mpa) \pm SD } \\
\cline { 2 - 4 } & PBS/D & SBS/D & SBS/G \\
\hline \multirow{2}{*}{ AH Plus } & $3.95 \pm 0.55$ & $4.71 \pm 0.56$ & $3.81 \pm 0.62$ \\
& $\mathrm{C}^{*}$ & $\mathrm{C}$ & $\mathrm{C}$ \\
Sealer 26 & $2.81 \pm 0.57$ & $3.01 \pm 0.55$ & $2.41 \pm 0.52$ \\
& $\mathrm{~B}$ & $\mathrm{~B}$ & $\mathrm{~B}$ \\
Endofill & $1.60 \pm 0.43$ & $1.8 \pm 0.62$ & $1.42 \pm 0.53$ \\
& $\mathrm{~A}$ & $\mathrm{~A}$ & $\mathrm{~A}$ \\
\hline
\end{tabular}

"The different letters vertically mean significant difference exist.

Table (3): Failure mode among tested endodontic sealers by different BS tests.

\begin{tabular}{|c|c|c|c|c|c|c|}
\hline \multirow[b]{2}{*}{$\begin{array}{l}\text { Tested } \\
\text { Sealers }\end{array}$} & \multirow[b]{2}{*}{$\begin{array}{c}\text { BS } \\
\text { Tests }\end{array}$} & \multicolumn{5}{|c|}{ Failure Mode \% } \\
\hline & & $\begin{array}{c}\text { Adhesive } \\
\text { S/D* }\end{array}$ & $\begin{array}{c}\text { Adhesive } \\
\text { S/G** }\end{array}$ & $\begin{array}{c}\text { Combination } \\
\text { Adhesive } \\
\text { S/D and S/G }\end{array}$ & $\begin{array}{c}\text { Cohesive } \\
\text { at } \mathrm{S}\end{array}$ & Mixed \\
\hline \multirow{3}{*}{ AH Plus } & PBS & 20 & ------- & ------- & -------- & 80 \\
\hline & SBS/D & 20 & ------- & -------- & ------- & 80 \\
\hline & SBS/G & -------- & 30 & -------- & -------- & 70 \\
\hline \multirow{3}{*}{ Sealer 26} & PBS & 30 & ------- & ------- & ------ & 70 \\
\hline & SBS/D & 30 & ------- & ------- & ------- & 70 \\
\hline & SBS/G & ------- & 40 & ------- & ------- & 60 \\
\hline \multirow{3}{*}{ Endofill } & PBS & 60 & ------- & ------- & -------- & 40 \\
\hline & SBS/D & 70 & ------ & ------ & ------ & 30 \\
\hline & SBS/G & -------- & 70 & ------- & ------- & 30 \\
\hline
\end{tabular}

*S/D: sealer/dentin. **S/G: sealer/gutta perch. 

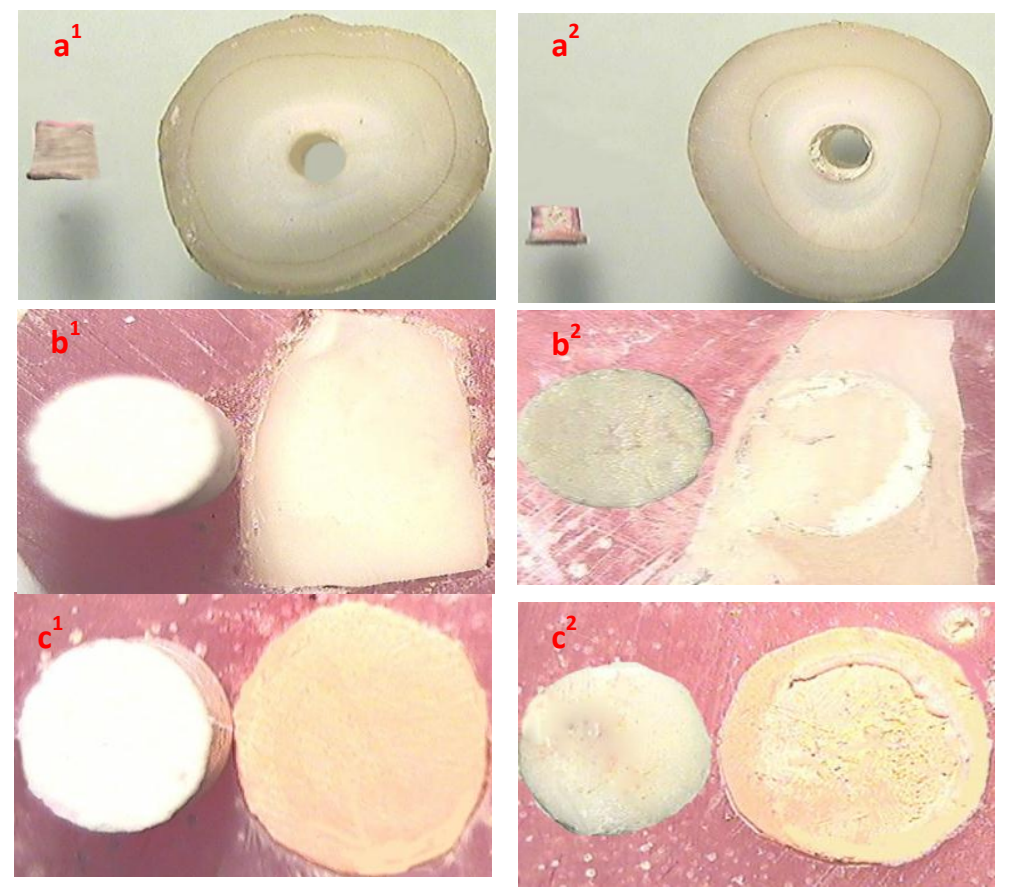

Figure (5): Mode of failures among different bond strength. $\left(a^{1}, a^{2}\right)=$ PBS/D. $\left(a^{1}\right)=$ Adhesive failure. $\left(a^{2}\right)=$ mixed failure.

$\left(b^{1}, b^{2}\right)=$ SBS/D. $\left(b^{1}\right)=$ Adhesive failure. $\left(b^{2}\right)=$ mixed failure. $\left(c^{1}, c^{2}\right)=$ SBS/G. $\left(c^{1}\right)=$ Adhesive failure. $\left(c^{2}\right)=$ mixed failure.

\section{DISCUSSION}

Obtaining a hermetic seal of the root canal system with an inert, biocompatible material is the main goal of a successful endodontic treatment. The most common obturating material is $\mathrm{G}$ which does not bond to $\mathrm{D}$ walls. Therefore in order to attain an ideal seal, G should be used with a sealer. In addition, adhesion of root canal sealer to both $\mathrm{G}$ and root $\mathrm{D}$ would be desirable in obtaining a hermetic seal that could prevent microbial microleakage. ${ }^{(1,2)}$

In the last decades, the adhesion of endodontic sealers to $G$ and $D$ has been the subject of several studies. The methods to measure shear strength seem to be the simplest, most effective and reproducible. Theywere initially developed to evaluate the bonding of endodontic sealers to D and G. More recently, PBS is one effective method to evaluate the adhesive bond strength of an endodontic obturating material. ${ }^{(5,6,7,10)}$ Therefore these two tests were used in this study.

In present study, PBS was evaluate in root slices filled with sealer plus G. Because of, use of sealer alone is not recommended clinically for canal filling, and was included only to permit the separate measurement of the D/S interface BS. It had been revealed that resin based sealers undergo polymerization shrinkage, which may affect the quality of the bond to dentine and to core material. Also, during filling using a core material, sealer cement is generally present as a thin layer, with two interfaces: between (S/D) and S and the main cone. If the entire canal is filled with sealer, only one interface (S/D) is present so that the bond strengths after filling with sealer alone were higher than those with main cone and sealer. Also sealer may reflect different patterns of behaviour when it is present as a thin layer. ${ }^{(9)}$ So that if the sealer used to fill the canal alone this was confused about the exact BS of sealer to D and $\mathrm{G}$.

With the development of resin based sealers, the strength of the bond has received greater attention; the possibility of creating a 'monoblock' of sealer and core material that also bonds to the canal wall has introduced the prospect of strengthening the root filled tooth againstfracture. Therefore in current study EDTA used after $\mathrm{NaOCl}$ irrigation because of several studies 
demonstrated that using of EDTA after $\mathrm{NaOCl}$ irrigation increase bond strength of resin based sealer to D, because of EDTA is able to act on tooth mineral matrix and promote removal of the smear layer formed during biomechanical preparation, which allow a better penetration of sealers into the dentinal tubules, increasing the contact surface of the filling material with dentin. ${ }^{(6,8,9,10,11)}$

In this study PBS, SBS/D, and SBS/G of AH Plus and Sealer 26 significantly higher than Endofill. Using of EDTA as final rinse after $\mathrm{NaOCl}$ significantly enhance the bond strength of AH Plus and Sealer 26 than Endofill. This could be due to resin nature of these two sealer and as these irrigation had the ability to remove smear layer and then expose a mesh of collagen fibers in dentin matrix, this collagen mesh act as a substrate for resin which infiltrate the fibers and forms hybrid layer (sealer tags). ${ }^{(8)} \mathrm{Al}-$ so it was found in this study that in spite of using flat surface of $\mathrm{G}$, resin based sealers remain had good adhesion to $G$ than that of ZOE based sealer and this supported by several previous studies. ${ }^{(3,4,7)}$

Also it was found in this study that PBS, SBS/D, and SBS/G of AH Plus significantly higher than Sealer 26. This result from the fact that in addition to resin nature of AH Plus, it had good flow, expansion over time, long setting time, and there chemical composition were more stronger than that of Sealer $26 .^{(3,4,12)}$ which help it to penetrates deeper into the surface microirregularities, as well inside the lateral root canals. These properties lead to greater intertwining of the sealer with D structure, which together with the cohesion among the cement molecules, provides greater adhesiveness and resistance to dislodgment from D and G.

Predominance mode of failure of resin based sealers used in this study was mixed failure (adhesive and cohesive) at S/D interface and this was agree with ${ }^{(3,7,9)}$ and could be attributed to the insufficient amount of resin in a thin setting layer. Jainaen et al ${ }^{(9)}$ had reported that the resin matrix material preferentially penetrated the dentinal tubules, leaving a sealer layer that is enriched with filler particles that are larger than the dentinal tubule diameter.
This leaves a sealer with a resin-depleted layer and a filler particle enriched interface. If the sealer layer does not have sufficient bulk or thickness, the loss of resin into the dentinal tubules may not be compensated. A weak bond would result due to the excessively high particle ratio in the sealer layer, thus result in cohesive failure within the sealer; while adhesive failure at S/D interface may result from incomplete removal of smear layer by $\mathrm{NaOCl}$ and EDTA in which not all dentinal tubules were opened ${ }^{(8)}$ thus the resultant failure was mixed. But the most common mode of failure for Endofill sealer showed in this study was adhesive this might be due to that Endofill was ZOE based sealer and several studies ${ }^{(4,5,6)}$ revealed that ZOE base sealer had weak adhesion to the canal wall and $G$. Also it was found in this study that most common failures at $S / G$ interface were mixed failure for resin based sealers and adhesive failure for ZOE based sealer. This might result from superior flow, expansions rate, and chemical composition, of resin based sealer in comparisons with $\mathrm{ZOE}$ based sealer. ${ }^{(7,9,11,12)}$

Under the limit of this study, it can be concluded that AH Plus sealer had good adhesion to the canal wall and $G$ so the use of this sealer is recommended to obtained a successful endodontic treatment. Also it was found that the different BS tests were more sufficient to evaluate adhesion of root canal sealer to $G$ and $D$. This study was in accordance with several previous studies ${ }^{(3,5,6,7,9,10,12)}$ Who reported that $\mathrm{AH}$ Plus sealer had good BS to G and D among different sealers were tested either those based on calcium hydroxide, or on resin, and or those based on to ZOE.

\section{CONCLUSIONS}

Within the limitations of the present study, the following conclusions can be extracted: AH Plus sealer presented greater adhesion to $D$ and $G$ than Sealer 26 and Endofill. Predominance mode of failure for resin based sealers were mixed failure (adhesive and cohesive), while for Enodfill was adhesive failure. PBS and SBS tests were more efficient and sufficient tests for measuring BS of endodontic sealers to D and G. 


\section{REFERENCES}

1. Rai K, Hegde M, Heghe P. Apical sealing ability of newer resin based pulp space sealers- An in vitro. Endodont. 2009; 2:19-21.

2. Savariz A, Radriguez MPG, Luque CMF. Long term sealing ability of guttaflow versus $\mathrm{AH}$ plus using different obturation techniques. Med Oral Patol Oral Cir Buccal. 2010; 15:936-941.

3. Lee KW, William MC, Camps JJ, Pashley DH. Adhesion of endodontic sealers to dentin and gutta percha. J Endod. 2002; 28:684-688.

4. Khedmat S and Sedaghati M. Comparison of the tensile bond strength of four root canal sealers. J Dent. 2006; 3:1-5.

5. Bojar W, Czarncka B, Prylinski M, Walory J. Shear bond strength of epoxy resin-based endodontic sealers to bovine dentin after ozone application. Acta Bioeng Biomech. 2009; 11:41-45.

6. Salman RF and Behnam IN. Shear bond strength measurement of three different adhesive sealer to dentin and gutta percha (In Vitro Study). Zanco J Med Sci. 2010; 14: 1-5.

7. Teixeira CS, Alfredo E, Thome LH, Silva RG, Sousa YTC, Neto MD. Adhe sion of an endodontic sealer to dentin and gutta- percha: shear and push-out strength measurements and SEM analysis. JAppl Oral Sci. 2009; 17:129-135.

8. Fayyad DM and Darrag AM. Effect of different irrigating solutions on push out bond strength of resin obturation system. Cairo Dent J. 2007; 11:149-157.

9. Jainaen A, Palamara JEA, Messer HH. Push-out bond strengths of the dentinesealer interface with and without a main cone. Int Endod J. 2007; 40:882-890.

10. Gesi A, Raffaelli O, Goracci C, Pasbley DH, Tay FR, Ferrari M. Interfacial strength of resilon and gutta percha to intraradicular dentin. J Endod. 2005; 11:809-813.

11. Lee B, Lai EH, Liao K, Lee C, Hsieb K, Lin C. A novel polyurethane-based root canal obturation material and urethaneacrylate-based root canal sealer-parts 2 : evaluation of push -out bond strengths. J Endod. 2008; 34:594-598.

12. Steier L, Figueiredo JAP, Belli S. Comparisons of the interface dentineendodontic sealer using two SEM magnifications. Rev Odonto Cienc. 2010; 25:296-299. 